\title{
África mártir, continente e Iglesia
}

\author{
Jean Floribert Kabemba, \\ República Democrática del Congo.
}

Ante todo, quiero expresar mi profundo agradecimiento a las autoridades de la UCA y a los organizadores de este congreso por la invitación a hablarles a ustedes como africano. Uno de los organizadores me dijo que esta ponencia es, sobre todo, un momento para compartir mi experiencia en África con un pueblo y una Iglesia, aquí en El Salvador, que tienen, como ustedes saben muy bien, una larga experiencia de martirio.

Vivimos en un mundo de globalización, pero al ritmo del capitalismo norteamericano, y mi país no vale mucho. Es explotado, y de él no se habla mucho, porque las potencias nos mandan callar. Por eso, desde el principio quiero agradecerles el amor y la solidaridad que muestran con el pueblo africano.

Quisiera decir ahora unas palabras sobre el contexto personal de mi ponencia. Personalmente, ya desde que estaba en el seminario menor, oí hablar de Monseñor Oscar Romero y de muchos otros mártires de América Latina. También conocí algunos nombres de obispos, como el de don Hélder Camara, pero no conocía mucho de sus vidas y sus actuaciones concretas.

Ahora tengo la oportunidad de celebrar con ustedes salvadoreños y con los hermanos y hermanas, que han venido de otros países, el XXV aniversario del asesinato-martirio de Monseñor Romero. Me impacta estar aquí, porque descubro el significado profundo y evangélico de la entrega a un pueblo crucificado, entrega que ha generado muchos mártires, en particular a Monseñor Romero.

Además, encuentro aquí profundas semejanzas con otros mártires africanos, de quienes hablaremos después, como el arzobispo Munzihirwa, a quien en Africa llamamos el "Oscar Romero de África". El arzobispo Munzihirwa sigue vivo en nuestro pueblo, y de esa forma, Monseñor Romero vive no sólo en el pueblo salvadoreño, sino también en África. Como él mismo dijo, "si me matan, resuci- 
taré en el pueblo salvadoreño"1. Y eso ocurre con todos los mártires. Los mártires viven cuando seguimos sus pasos. Recogiendo la sabiduría africana, decía Monseñor Munzihirwa: "la mejor forma de llorar un muerto es cultivar su cam"po"2. Aquí está, en mi opinión, el sentido más profundo de este congreso y de la celebración del XXV aniversario del martirio de Monseñor Romero.

Quisiera hacer ahora una segunda reflexión previa. En el actual contexto africano, no es suficiente hablar de mártires como cristianos heroicos que murieron por la causa de la fe, in odium fidei - ¡hay tantos en África! -, sino que ayuda más comprenderlos desde un continente que ha sufrido por causa de la injusticia, in odium iustitiae, según la distinción que hace Jon Sobrino. Por ello, para hablar del martirio hay que hablar de África y del encuentro con sus "victimarios", es decir, del choque con la cultura occidental, que comenzó hace varios siglos y que continúa con el actual enfrentamiento con el neoliberalismo. En el análisis de este choque cultural nos fijaremos en dos ámbitos. Uno es el ámbito histórico, político-económico. El otro es el ámbito eclesial con su proceso de evangelización y la actuación de su jerarquía.

Dividiré la ponencia en tres partes: África: continente olvidado y martirizado, a lo largo de la historia y en el marco actual de la globalización; la Iglesia de África: fuente de "martirio" y de "testimonio", en la época de la misión evangelizadora, en el tiempo de la colonización y frente a los desafíos del mundo actual; y los mártires africanos: semilla de esperanza para una nueva humanidad. "Otra África es posible", como resultado de los compromisos de la Iglesia con sus pueblos.

\section{1. África : continente olvidado $\mathrm{y}$ "martirizado"}

En muchos aspectos de la vida, la realidad de África refleja una crueldad, que bien puede expresarse con el término "martirio". El continente africano sigue viviendo, de una u otra forma, la discriminación y el desprecio de toda una raza. Parece que se le niega hasta el derecho de ser cuna de la humanidad, que le viene por la naturaleza.

\subsection{La realidad sociocultural}

Desde los primeros momentos en que llegaron los colonizadores hasta el reparto de África que hicieron en forma de naciones, África ha sido vista desde un prejuicio fundamental: es una raza infrahumana. $Y$ ha sufrido las consecuencias: la esclavitud y la negación de su dignidad, que culminó con el sistema colonialista

1. Citado en R., Cardenal, I. Martín-Baró y J. Sobrino, La voz de los sin voz, San Salvador, 1980, p. 461.

2. Estas palabras son el logo de $A$ Fondo. Grupo Munzihirwa, Información alternativa. Africa Central. 
sudafricano del apartheid. Un ejemplo. "En África, a los imponentes reyes y majestuosas reinas, que habían nacido como clase social alta, se les arrebató su grandeza cuando quienes martirizaron su continente los redujeron, junto a sus pueblos, a la esclavitud (como fue el caso de los reyes zulú de Sudáfrica)"3. Parecía, en realidad, que el negro africano no tenía derecho a vivir y a ser considerado como un ser humano, lo cual ha supuesto la destrucción casi total de todo un pueblo, al cual no lo han dejado que tome el rumbo de su historia, porque no valía nada.

Mucho se ha dicho ya que la esclavitud es el peor de los empobrecimientos, el mayor de los "martirios", el llamado "martirio ontológico", o dicho con más precisión, el "empobrecimiento antropológico", que influye hasta en la manera de ser visto por otros y de verse uno a sí mismo como negro. Hoy, todavía continúa el desprecio, y lo podemos ver en sociedades multiculturales como la de Estados Unidos. Esto aparecerá claro en todos los ámbitos importantes de la vida, y también, como veremos, en la evangelización misionera. El elemento fundamental de la lucha de la teología africana, inspirada en la teología latinoamericana de la liberación, consiste precisamente, en buscar la liberación de ese martirio ontológico y de esa pobreza antropológica.

Tras el martirio socio-cultural siempre ha habido intereses. La teóloga nigeriana Teresa Okure se pregunta: "ipor qué Europa consideró beneficioso el martirio de África, en la época del comercio de esclavos? Ciertamente, porque la prosperidad y la supervivencia del 'nuevo mundo' de los blancos dependían de ese martirio. Para poder acometer el martirio con una conciencia tranquila, fue necesario elaborar una teoría, según la cual los africanos eran una especie subhumana, gente sin inteligencia, sin cultura, ni humanidad, e incluso, sin alma"4. De ahí surgen nuevas formas de esclavitud, que han llegado hasta el día de hoy, promovidas por intereses económicos y religiosos, como es ahora, por ejemplo, el caso de Sudán con la explotación de los niños entre países árabes. "La esclavitud y el comercio de seres humanos siguen existiendo en el mundo y, especialmente en África, donde se revisten de múltiples formas. Cada año son vendidos en el mundo cerca de $1,200,000$ niños, un negocio que genera unos beneficios de unos 10,000 millones de dólares"s.

\subsection{La realidad político-económica}

Lo más fuerte de la explotación se nota en la economía de África, hasta tal punto que, en nuestro continente, no podemos saber quiénes dirigen nuestros países. La política que impulsan está inspirada en occidente -o es dictada por

3. Teresa Okure, "África, un continente martirizado: semilla de nueva humanidad", Concilium 299 (2003) 44.

4. Ibid., p. 45 .

5. José Luis Cortés López, “¿Hay todavía esclavos?”, Mundo negro, 494 (2005) 20. 
éste-, sin tener en cuenta ningún fundamento sociocultural tradicional africano. Lo cierto es que los dirigentes políticos que nos imponen, facilitan el saqueo de las multinacionales, porque ellos, a su vez, también obtienen beneficios. Son verdugos que hacen que aumente el número de "victimarios". "Como los amos colonialistas gobernaron África, mediante el saqueo de sus recursos y el desprecio hacia la gente, así también sus sucesores africanos, convencidos de que la forma de gobernar que tenían los europeos es la mejor de todas, siguen imitando su estilo, saqueando la herencia y las riquezas de sus naciones y destinándolas a Occidente en lugar de invertirlas en sus propios países"6.

Hoy, en África están los países más pobres del mundo, siendo así que no le faltan recursos naturales, minerales, culturales y humanos. Algunos países, para conseguir sus intereses partidistas, desencadenan guerras, aprovechándose de la debilidad de muchas etnias. Hay muchas guerras que no tienen ningún sentido, como la de la región de los Grandes Lagos, en nuestros días, causada por la avaricia de las multinacionales para apoderarse del nuevo mineral colombo platinium (coltán), así como de otros recursos, diamantes, oro, cobre, uranio, madera, etc. Ha habido - y hay - genocidios con muchas víctimas de las que nadie habla. Así lo afirman, refiriéndose a la República Democrática del Congo, los autores del librodisco El genocidio del que no se habla ${ }^{7}$. Y hay muchos otros genocidios y víctimas silenciadas. Desde esta perspectiva, hay que insistir en el elemento criminal del neoliberalismo, por lo que produce: empobrecimiento constante, en casi todos los países africanos; la deuda externa, llamada también deuda eterna...

Los 300 billones de dólares que los países africanos "deben" a acreedores extranjeros son cargas muy pesadas para los gobiernos y la gente del continente. Cada año, las naciones africanas emplean 15 billones de dólares en devolver la deuda a los países ricos y al Banco Mundial..., cuando son fondos que se necesitan desesperadamente para el desarrollo, la educación, la erradicación de la pobreza y la lucha contra el SIDA y otras enfermedades evitables, y que se emplean para devolver los préstamos e intereses, algo que la pobreza de África no se puede permitir. Por cada dólar recibido en ayudas, desde 1999, el África subsahariana devolvió 1.51 dólares como cancelación. África emplea en devolver la deuda cuatro veces más de lo que destina al cuidado de la salud. Se dice también que cada uno de los 1.5 millones de niños de Kenya lleva consigo una deuda de 500 dólares $^{8}$.

6. Teresa Okure, op. cit., p. 48.

7. José García Botía y otros, El genocidio del que no se habla. Guerra en la República Democrática del Congo, editado por la Federación de Comités de Solidaridad con el África Negra y Asociación cultural Veredas.

8. En A Fondo, Grupo, 2 (2005) 2. 
Y no se suele hablar de las víctimas de esta política internacional del comercio y de explotación en toda África.

\section{La Iglesia de África: martirio y testimonio}

Vayamos ahora al ámbito religioso y de su teología. A través de ciertas formas de pensamiento teológico, también la Iglesia ha sido un instrumento de propagación de ideologías, que causan sufrimientos al pueblo africano. Lo analizaremos en las distintas etapas de evangelización misionera. Y digamos que usamos el término de "martirio" por la hondura de los sufrimientos que infligió la Iglesia a los pueblos africanos y porque, junto a esos sufrimientos, se facilitaba la "muerte" cultural.

\subsection{Las etapas del "martirio", a través de la evangelización misionera}

\subsubsection{El encuentro y colisión del cristianismo con África}

Esta etapa está marcada por el primer encuentro histórico entre la fe cristiana, traída por el misionero, y las tradiciones culturales, que fueron etiquetadas como animismo, diabolismo o paganismo.

El encuentro fue brutal, ya que no se aceptó, ni se permitió al africano expresar sus realidades y experiencias religiosas, en las que, a su manera, celebraba su fe. La proclamación de la fe cristiana no tuvo en cuenta la dignidad, ni la existencia de un pueblo, que vive en un universo cultural propio y con sus propios valores. Las diversas dimensiones del discurso colonial nos mostrarán el tipo de espiritualidad que se fue propiciando a lo largo de esa etapa. Más que un encuentro fue una colisión, en la cual se impuso un discurso colonial totalitario. Consciente o inconscientemente, la labor del evangelizador estuvo mezclada con la del colonizador y con sus intereses. La consecuencia fue que el misionero quedó confundido con el blanco que venía a invadir.

Hijo de su tiempo, el modo de concebir el misionero la acción de Dios en el mundo era, semánticamente, una imposición, a través del lenguaje, al servicio de mostrar la superioridad de toda la cultura occidental sobre el negro, considerado todavía en la edad de piedra. El misionero no era capaz de vivir y de pensar de otra manera que no fuera la de transmitir los elementos de una sociedad civilizada, según sus criterios, a unos pueblos que vivían todavía en una etapa relativamente inadecuada para el nivel de vida del colonizador. De esa manera, el misionero pionero y evangelizador de los países conquistados asumió el discurso de su tiempo. Para el teólogo congoleño, Oscar Bimuenyi, no hay duda de que el misionero pensaba como el conquistador. Los negros vivían en la perdición, según la fe cristiana.

Las consecuencias de ese encuentro fueron desoladoras, pues se destrozababa así la personalidad cultural, profundamente religiosa, de todo un pueblo, 
dejando las huellas de un inmenso desastre cultural. ¿Qué quedó de aquellos pueblos colonizados? Quedaron sin tierra, porque todos sus territorios fueron divididos, sin su consentimiento; sin historia, ni tradición, porque no existía nada bueno que debía ser conservado, desde el punto de vista del misionero; sin pueblo, porque los que valían iban a servir a los trabajos de las plantaciones en América.

Todo esto no ocurrió sin que la conciencia de los conquistadores buscase una justificación. Incluso había que tener la bendición de Dios, o al menos del Vaticano, que enviaba misioneros. Lo muestran los discursos teológicos.

\subsubsection{Las etapas de la teología colonial}

En el contexto descrito, la misión ha sido muy ambigua, hasta el punto de que el mensaje, que el misionero iba anunciando, perdió su identidad. El discurso teológico, en efecto, daba pautas, e incluso ánimos, a la obra del colonizador. Lo que hacía el misionero no era, en definitiva, más que liberar a los negros del dominio de satanás, lo cual animaba al colonizador a comprender su tarea también como liberación. La labor del colonizador, por su parte, con ambiciones distintas, tenía el mismo interés de invadir pueblos para liberarlos, civilizarlos o anexarlos a la cultura del colonizador.

En la "liberación" convergían los intereses de unos y otros. De esa forma, el mismo mensaje de la Biblia iba a justificar la maldición de todo un pueblo, que necesitaba ser liberado, gracias a la obra benéfica del misionero. Pero el Cristo salvador fue revestido de un traje colonizador, y el mensaje del evangelio también fue manipulado por unos intereses, en este caso, de los colonizadores. Veamos cómo se ha ido pensando teológicamente ese primer momento del encuentro con África, para mantener y justificar lo que pensaban ser una causa "noble".

Teología de la "salvación de las almas" o de la "conversión de los infieles": la tabula rasa.

Cuando con la evangelización se erradicó la presencia del demonio, ya se podía introducir - y había que hacerlo - el elemento central de la obra misionera: la cultura y la religión occidental. En efecto, en los decretos y textos de los romanos pontífices se explicaba a los misioneros la importancia de su tarea: salvar a los "pobres endemoniados". A modo de ejemplo, recordemos la bula del Papa Nicolás V al rey Alfonso de Portugal, en la cual se alegraba de que esclavos negros fuesen bautizados in copioso numero", sacados por la fuerza de "las garras del demonio" y así obtener la salvación ${ }^{10}$.

9. Bimuenyi Kueshi, Discourse théologique negro-africain. Problem des fundaments, París, 1981, p. 155.

10. El papa Benedicto XV, en la instrucción Quo efficacius, del 6 de enero de 1929 , hablaba de "almas a ganar". Pío XI decía que los misioneros "deben ayudar a las almas y solamente a las almas". 
Estos textos presuponían una concepción dualista del mundo, dividido en la parte visible y la parte invisible. De la misma manera, el ser humano tiene una parte visible, el cuerpo, de la cual no había que preocuparse mucho; y otra parte invisible, el alma, el centro de toda la persona y lo que hay que tener en cuenta en la obra de la salvación. Según esto, desde el principio se hizo hincapié en las celebraciones, que remiten a la parte espiritual de la persona, pensando salvar con ello la parte más importante del ser humano. Sin embargo, eso no encajaba en absoluto con el pensamiento filosófico del africano, que vive en simbiosis con la naturaleza. El hecho de no considerar la personalidad cultural de un pueblo, en la concepción y actuación del evangelizador, tuvo nefastas consecuencias, en los juicios sobre valores culturales. De hecho, era poner a todo un pueblo en camino hacia el martirio cultural.

A juicio del misionero, en efecto, no había en África una experiencia cultural, un caminar propio y unas aspiraciones fundamentales a tener en cuenta. La obra misionera era casi, como dice el teólogo Oscar Bimuenyi, una "operación de rescate, de tipo humanitario, para sacar a los rehenes detenidos por satanás; incluso un tipo de FAO sobrenatural enviando cajas de alimentos para los desnutridos espirituales" "'. Aquí aparecen claramente las graves consecuencias de la obra misionera de aquella época. Ésta estaba caracterizada por una división interna. Por un lado, estaba el misionero, hombre blanco, transmisor de una ideología colonial, y no un hermano con quien dialogar. Por otro, estaban los ancianos - símbolo de la sabiduría y transmisión de la cultura y de la fe-, empeñados en defender sus tradiciones culturales, ante un hombre blanco, que venía a quitarles todo para imponerles su manera de pensar y de vivir.

Hoy, queda claro el fracaso de una obra misionera que, desde el inicio, se llevó a cabo sin diálogo y, por lo tanto, desde el mismo comienzo, sólo fue superficial. Más aún, es claro que la misión fue una empresa de pretendida civilización y no de proclamación del mensaje evangélico, lo cual pone más de relieve la dimensión monopolizadora de la cultura occidental: sólo hay un mundo, una civilización, una cultura, un modelo de desarrollo, el de occidente. Mutatis mutandis, habrá un solo tipo de espiritualidad bien definida: la traída por el misionero, ya que no hay más que una sola religión, la de los conquistadores, y una sola espiritualidad, la del occidente.

No es de extrañar que, ante esta forma de misionar, surgieran reacciones brutales, lo que fue un claro signo del fracaso de la misión y de la falta de convivencia entre europeos y africanos. Eran de esperar reacciones, como la del kimbanguism, o Iglesia de Jesucristo en la tierra, considerada actualmente como religión, y no como secta, porque es miembro de la Asamblea Ecuménica de las Iglesias del Congo. Lleva el nombre del fundador Simón Kimbangu, de tenden-

11. Bimuenyi, op. cit., p. 159. 
cia espiritualista, que predicaba la liberación cultural y política del dominio occidental, a partir de la lectura de la Biblia. Por su parte, doña Beatriz, cuyo destino fue parecido al de Juana de Arco, fundó la secta del antonismo. Su suerte acabó con la muerte.

Teología de la "implantación de la Iglesia", plantatio ecclesiae: un traje no tallado a la medida.

El título lo dice bien. La teología de la implantación quiere ofrecer un nuevo rostro de la Iglesia en África, pero copiando simplemente para ello la estructura europea de la Iglesia y trasladándola a África. Completada la tarea de limpiar todo lo que era pagano, había que traer de Europa una nueva eclesiología para los indígenas, con lo cual se ponían en marcha nuevas estructuras, pero eran las de una organización lejana a la concepción del mundo africano.

En el Vaticano se elaboraron muchos textos con la finalidad de invitar al misionero a implantar en África una nueva cúpula, fiel a las recomendaciones de Roma. Iba a nacer una nueva Iglesia, semejante a la de occidente, en cuanto a su "personal y sus obras, así como en sus metodologías". De esta forma, la Iglesia iniciaba una nueva etapa donde se veía claramente su preocupación monopolizadora y uniformista. Quedaba claro que "fuera de la Iglesia católica no hay salvación". De este modo, ignorando el universo cultural africano, tan diferente, se trataba de implantar un modelo único, con sus estructuras, y sin preocuparse del receptor del mensaje.

Nace así una dicotomía en la estructura misma de la Iglesia: no hay respeto por las culturas africanas, en el proceso de la evangelización, y se construye una figura de Iglesia calcada de la europea. El jesuita camerunés F. Eboussi dice que "las jóvenes iglesias han nacido viejas, parecidas a los castillos medievales que los ricos americanos transportan, piedra por piedra"'2. Todavía no hemos salido de esta situación, como aparece en la manera habitual de actuar de nuestros pastores.

A estas nuevas Iglesias locales no se les llevó el mensaje evangélico en sí, sino que se transplantaron y se les impusieron las culturas de otras naciones extranjeras, dejando a un pueblo destrozado. Como consecuencia, la estructura de la Iglesia quedó como algo ajeno a África, lo cual hizo pensar a los autores de Tierra africana y sus religiones que, en el fondo, el cristianismo ha sido la "religión de los blancos", porque realmente es muy ajena al continente africano y a sus aspiraciones profundas.

Con esa estructura, África adquirió un nuevo traje, que no le servía, porque no sabía qué hacer con él y con qué medios habría de mantenerlo. En la actualidad, pensamos, persiste la misma estructura. Los nuevos protagonistas intentan defenderla por todos los medios, pero un edificio ya hecho, que mantiene inclu-

12. F. Eboussi, citado por Oscar Bimuenyi, op. cit., p. 166. 
so una importante dependencia financiera, difícilmente podrá cambiar. Este es uno de los retos que, hasta el día de hoy, tiene la Iglesia de África. Y parece que nadie puede liberarse de la estructura establecida con sus normas y sus reglas de juego.

Para superar esa Iglesia copiada de la europea han surgido nuevas teologías, que reconsideran la comunidad, desde la perspectiva del universalista del pueblo de Dios, proclamado por el Vaticano II. Esto significa que no será posible una espiritualidad fuera de la espiritualidad universal. Todos los movimientos de apostolado deberán reflejar el mismo modo de vivir la fe cristiana. Pero ¿quién era capaz de explicar las tradiciones de una Iglesia, que era ajena a África? El carácter de "ajeno a Africa" debería desaparecer para ofrecer un nuevo rostro de una Iglesia africana, y para ello, había que buscar, en las mismas tradiciones culturales africanas, lo que es compatible con la fe cristiana.

\section{Teología de la adaptación: reconsideración cultural.}

El carácter extranjero de la eclesiología ha sido muy fuerte, y por ello, llegó incluso a ser rechazado dentro de la Iglesia, dando lugar a movimientos de espiritualidad propios. La nueva teología iba a atenuar su carácter importado para dar un rostro indígena a la nueva Iglesia. Es la teología de la adaptación.

El discurso de la adaptación quiere tener en cuenta al otro, el destinatario del evangelio, en su originalidad. Aquí hay un cambio en la concepción de la labor pastoral y de la misión. Algunos aspectos de la vida del pueblo tienen que ser tomados en cuenta, por respeto a los valores culturales que el evangelio no viene a destruir. Eso significaba que la Iglesia intentaba acomodar la forma de ser de la Iglesia occidental a la cultura africana para que así se reflejase la nueva orientación de toda la Iglesia, hacia los nuevos pueblos con que se encontraba. Esto se notó en el ámbito de la liturgia, en la cual se introduce nuevos elementos, como la danza africana, el tam-tam, acompañados también de nuevos elementos de moral, todavía escasos. El lenguaje común de esa etapa va a ser la africanización, la indigenización o la naturalización del evangelio.

Se olvida, sin embargo, que el evangelio que se proclama sale al encuentro de todo un pueblo, con una cultura única y global, que no puede ser separada de la totalidad de la realidad africana. Poco a poco se fueron notando las incongruencias de una teología de la adaptación porque, en la realidad, era como un añadido de lo "africano o de lo asiático" a lo "germano-latino".

Había que cambiar. Los obispos africanos y de Madagascar, reunidos en el cuarto sínodo en Roma, en 1974, empezaron a hablar incluso de la eclesiología de la comunión y de la corresponsabilidad, siguiendo las directrices del Vaticano II. Se fue dejando de lado el concepto de adaptación, el cual fue sustituido por una teología de la encarnación del mensaje de Jesús, en todo un pueblo. Al retomar este tema, en el ámbito de las conferencias episcopales, surgieron los caminos de una teología en verdad africana y de celebraciones propiamente 
africanas, que consideraban la realidad globalizante. Para los obispos se trata de tener en cuenta a las comunidades cristianas africanas, que reciben el mensaje, desde sus problemas fundamentales, así como de su contexto sociocultural específico. Es todo un pueblo de Dios, viviendo su dinamismo cultural, el que se encuentra con el mensaje de Jesús.

Para Oscar Bimuenyi es toda la "cultura en su conjunto la que, desde el interior, se purifica bajo la acción fecunda del evangelio", creando nuevas expresiones del dinamismo de toda una Iglesia, que empieza a proclamar su fe de una manera totalmente nueva y distinta. De esta forma, se expresa el carácter global de un pueblo, que reconsidera su universo cultural como un todo y no como una parte separada del todo, y eso es lo que da esperanza para formar una Iglesia. Toda la fe y todo el evangelio se mueven dentro de un pueblo que los recibe y hace suyos sus elementos fundamentales dentro de su cultura.

La conclusión es que hay que superar una teología de la adaptación, que acaba construyendo una estructura y una espiritualidad de fachada, que no llega al interior de todo un pueblo. No es, por lo tanto, una solución duradera, aunque muchos intentaron justificarla a su manera. Lo que realmente se descubre en estas teologías es un modo de pensar bajo la tutela de otros. Es un reflejo fiel de un tipo de teología y de cultura ajena al mundo africano.

De hecho, sin embargo, esta tendencia hacia el universalismo intolerante persiste porque, además, existe una dependencia material respecto de occidente, que sigue imponiéndose, a través de las nuevas figuras de la Iglesia. El camino hacia una evangelización profunda tiene que ser otro. Tiene que respetar toda la cultura de un pueblo y asumir sus concepciones y todo su mundo de actuación.

\subsection{El testimonio del martirio, a través de la cultura}

En este contexto la historia del "martirio" eclesial en África interpela a nuestra Iglesia, a pesar del conformismo con las reglas habituales de la cúpula romana. Así como decimos de Mons. Romero que "creyó en el Dios de los pobres"13, la Iglesia de África no puede estar fuera del lugar donde sufren los pobres, en la realidad de una África empobrecida. Este es el lugar privilegiado, en el cual los pastores pueden encontrar a Dios, "desde y en los pobres", a la manera de Mons. Romero. Veámoslo en algunos ejemplos.

\subsubsection{Los héroes y mártires de hoy: Mons. Munzihirwa}

Así como Mons. Romero, profeta de Dios y pastor de los pobres, vivió su martirio, así Mons. Christophe Munzihirwa, arzobispo de Bukavu, República Democrática del Congo, desde 1986, y asesinado, el 29 de octubre de 1996, vivió

13. Jon Sobrino, Monseñor Romero, 1989, p. 75. 
también el suyo. Fue un profeta que denunció las condiciones infrahumanas, en las que vivían los refugiados rwandeses, en su diócesis, especialmente en Bukavu, y las causas que habían generado estos masivos desplazamientos de Rwanda al Congo. Con voz firme y claridad de pensamiento, denunció a los países occidentales, en concreto a Estados Unidos, que apoyaba al gobierno de Rwanda. Los testimonios de amor a los pobres y de trabajo por la paz han sido numerosos. Su sangre fue derramada y hoy sigue clamando por la paz, en la región de los Grandes Lagos.

Además de mártir, en nuestra cultura, Munzihirwa puede ser considerado como un héroe de la paz y de la convivencia, y de esa forma, pertenece al árbol de los antepasados. Desde una perspectiva cristiana y eclesial, no tenemos ninguna dificultad, ni impedimento, al menos moral, para invocarlo así, porque, de acuerdo a nuestra religiosidad africana, creemos que él está en Dios e intercede por nosotros. Al comenzar cualquier rito congoleño, nombramos a cualquiera de nuestros antepasados. Munzihirwa merece ser nombrado como uno de ellos.

\subsubsection{Los mártires colectivos: pueblo crucificado y siervo de Jahvé}

Entre nosotros hay numerosos sacerdotes, religiosos, religiosas, laicos, mujeres, que entregan su vida por la causa de África y defienden la causa de los pobres. Este pueblo crucificado "produce indignación y horror, pero los mártires, los que se han puesto a su servicio, producen ánimo y esperanza"14. No podemos concebir otro camino para la Iglesia que el de vivir al lado de los que más sufren, es decir, de los que más necesitan de su compromiso. Los mártires colectivos en África van a juzgar la conducta de la Iglesia, si creemos en el modo como juzga Dios.

De estos mártires hay que destacar a la mujer, la discriminación y la violencia que sufren, en el marco de la cultura machista, y las terribles consecuencias de tantas guerras y tanta explotación. Baste citar un testimonio del congoleño Somo Mwaka Silvestre, que vive en el este de nuestro país. "En el África de los grandes lagos asistimos a auténticas atrocidades hechas a las mujeres: la violencia sexual es utilizada como arma de guerra. Las mujeres se convierten en medio de transporte de los botines conseguidos en las batallas y son violadas, en todo momento. En la República Democrática del Congo, por ejemplo, un informe de Amnistía Internacional sobre la violencia sexual, publicado el año pasado, habla de por lo menos cinco mujeres (o muchachas) violadas cada minuto. Por si eso fuera poco, los cascos azules de Naciones Unidas también han cometido actos de violencia sexual, en la República Democrática del Congo"15.

14. Carta a las Iglesias 460 (2000) 21.

15. A Fondo, 3 (2005) 4. 
En esta realidad de sufrimiento, el jesuita camerunés Engelbert Mveng pronunció estas palabras programáticas. "La Iglesia africana está íntimamente liga¿da al futuro del continente, que está a punto de hundirse. Si África se hunde, la Iglesia se hunde con ella". Y sacaba la conclusión: "para las iglesias de África, el anuncio de la liberación, de la Buena Nueva a los pobres, los débiles y oprimidos es la prioridad de las prioridades"16.

\section{Los mártires africanos: semilla de esperanza para una nueva humani- dad}

El continente africano tiene muchos valores, que los mártires han defendido a lo largo de la historia. Viendo cómo aumentan las guerras y la injusticia en el mundo de hoy, es necesario escuchar las voces que gritan desde África.

En África, los valores supremos de la vida y de la solidaridad son sagrados. Muchos pueblos siguen respetando la vida de toda persona, mientras el terrorista o el kamikaze no se preocupa de nada. La vida es un lazo que une a todos los seres humanos, porque todos la reciben gratuitamente y la comparten. Es una vida "integral". Es vida "individual", al ser recibida por cada persona, y es vida "comunitaria", porque procede de una misma y única fuente. Existe la solidaridad entre los seres humanos y los miembros de la familia, porque se recibe en común el anhelo de la vida. Existe una unión vital entre los dos mundos, el actual y el de los antepasados, y entre todos los seres humanos, porque ese anhelo se transmite de uno al otro, de tal modo que entre la vida y la muerte no hay ruptura, sino continuación.

Y digamos, para terminar, que cada vez más el entorno de los seres humanos es visto como un universo, que es respetado al estilo africano: el ser humano necesita vivir y respetar la naturaleza. Es algo sagrado, que no se puede despreciar. Y sagrados son los seres humanos: los gritos de los que sufren, por culpa de los demás, siempre interpelan y claman justicia.

\section{Conclusión}

El camino del martirio en África ha sido, y sigue siendo, muy largo y complejo. Por un lado, no hay voluntad política para cambiar las políticas nacionales e internacionales. Por otro, la Iglesia tiene que estar en esa realidad, anunciando la buena nueva, de manera comprometida y no conformista, promoviendo pastores y profetas, tal como los necesita toda África.

Concluyo citando al teólogo camerunés Jean Marc Ela:

16. Palabras pronunciadas en la II Asamblea General de la Asociación Ecuménica de Teólogos del Tercer Mundo, diciembre de 1986, Oaxaca, México. 
África fue evangelizada en la tradición caritativa del cristianismo colonial, donde las obras benéficas alimentaban la buena conciencia. Los dispensarios, los hospitales, los orfanatos y las leproserías fueron implantados en las regiones donde los recursos de África se revalorizaban, en beneficio de las metrópolis. Hoy, los campesinos negros ya no trabajan para alimentarse con los productos que cultivan, sino para vender el algodón y los cacahuetes, el café y el cacao, que producen las divisas necesarias para el bienestar de las elites en el poder. ¿Por qué los cristianos de África no habrían de buscar con pasión la libertad de su pueblo, puesto que son los herederos del evangelio y de la misión de anunciarlo en su continente? Semejante responsabilidad exige que se ponga fin a una Iglesia centrada en sí misma, demasiado absorbida por los problemas de catequesis, de ritos matrimoniales y de organización material17.

17. Fe y liberación en África, Madrid, 1990, pp. 188-189. 